\title{
A SURVEY RESEARCH ON THE EFFECTS OF SALES PROMOTION, ANDADVERTISING ANDSTORE IMAGE ON CUSTOMERS' BUYING BEHAVIOR IN RETAILING
}

DOI: 10.17261/Pressacademia.2020.1252

PAP- V.11-2020(24)-p.121-126

Fatma Atigan

Mugla Sitki Kocman University, Mugla, Turkey.

fatmaatigan@mu.edu.tr, ORCID: 0000-0002-8838-3688

\section{To cite this document}

Atigan, F., (2020). A survey research on the effects of sales promotion, and advertising and store image on customers' buying behavior in retailing. PressAcademia Procedia (PAP), V.11, p.121-126

Permanent link to this document: http://doi.org/10.17261/Pressacademia.2020.1252

Copyright: Published by PressAcademia and limited licensed re-use rights only.

\begin{abstract}
Purpose- The aim of the research is to measure the effects of sales promotion and advertising and store image on consumer buying behav ior in clothing stores. The other aim is to investigate differences of these effects according to the consumers' demographic characteristics. Methodology- In the research, survey method was used in gathering data. Survey research was conducted in a department store in Mugla and 404 questionnaires were filled. The relations among variables were tested by Simple and Multiple Regression Analysis.

Findings- It's also determined that sales promotion and advertising and store image affect consumers' buying behavior positively, and the store image has an important role in this effect. Also it can be said that this common effect has differences by gender, age, marital status and education status of customers.

Conclusion- Based on these findings related to the research, it can be said that the sales promotion tools, advertisement and store image are effective in the customers' store preference and purchasing behavior, besides the importance of all three factors, a separate importance should be attached to the store image.

Keywords: Retailing, promotion, advertisement, store image, buying behavior .

JEL Codes: M3, M31, M37

\section{PERAKENDECILIKTE SATŞ TUTUNDURMA, REKLAM VE MAĞAZA IMAJININ MÜŞTERI SATINALMA DAVRANIŞINA ETKISI ÜZERINE BIR ARAŞTIRMA}

\section{ÖZET}

Amaç- Araştırmanın amacı, perakende giyim mağazalarında yapılan satış tutundurma faaliyetleri ve reklamlar ile mağaza imajının müşterilerin satınalma davranışındaki etkisini ölçmektir. Bir diğer amaç da, söz konusu etkinin, müşterilerin demografik özelliklerine gör e farklılık gösterip göstermediğini incelemektir.

Yöntem- Araştırmada veri toplama yöntemi olarak anket yöntemi kullanılmıştır. Anketler Muğla'da bir bölümlü mağazanın 404 müşterisine yüz yüze uygulanmıştır. Değişkenler arası ilişkiler basit ve çoklu regresyon analizleriyle test edilmiştir.

Bulgular- Değişkenler arasındaki ilişkiler incelendiğinde ise mağazanın satış tutundurma, reklam faaliyetlerinin ve mağaza imajının müşterilerin satınalma davranışını olumlu yönde etkilediği, mağaza imajının bu etkide daha önemli bir role sahip olduğu tespit edilmiştir. Ayrıca mağazanın tutundurma faaliyetleri ve mağaza imajının birlikte müşterilerin satınalma davranışına etkisinin müşterilerin cinsiyetlerine, yaş gruplarına, medeni ve öğrenim durumlarına göre farklılık gösterdiği ifade edilebilir.

Sonuç- Araştırmaya ilişkin bu bulgulardan yola çıkılarak, satış tutundurma araçları, reklam ve mağaza imajının müşterilerin mağaza tercihinde ve satınalma davranışlarında etkili olduğu, her üç faktörün taşıdığı önemin yanı sıra mağaza imajına ayrı bir önem verilmesi gerektiği söylenebilir.

Anahtar Kelimeler: Perakendecilik, tutundurma, reklam, mağaza imajı, satınalma davranışı. JEL Kodları: M3, M31, M37.

\section{Giriş}

Perakende mağazalar genellikle tüketicinin kolayca ulaşabilecekleri alanlarda kümelenmişlerdir. Bu durum benzer mal ve hizmet sunan mağazalar arasında ise rekabeti şiddetlendirmektedir. Müşterilere yönelik olarak farklılık yaratmak ve müşteri daha fazla dikkatini çekip satışları arttırmak amacıyla da satış tutundurma araçlarını ve reklamları kullanmaktadırlar. Dönem dönem yaptıkları reklam ka mpanyalarını fiyat indirimleri, yarışmalar, çekilişler, tanıtım amaçlı dağıtılan promosyonlar vb. uygulamalarla pekiştirmeye çalışmaktadırlar. Ancak gelinen 
noktada reklam ya da satış tutundurma araçlarının birlikte yetersiz kaldıkları hem uygulamada hem de yazında ifade edilmektedir. Mağazaların, daha fazla müşteriyi çekebilmek için yine söz konusu reklam ve satış tutundurma araçlarını kullanarak müşterilerin zihninde olumlu mağaza imajı yaratmaları gerekmektedir (Arslan ve Boyçu 2006:40). Bu önemden yola çıkılarak yapılan araştırmanın amacı, perakende giyim mağazalarında yapılan satış tutundurma faaliyetleri ve reklamlar ile mağaza imajının müşterilerin satınalma davranışındaki etkisini ölçmektir. Ayrıca, söz konusu etkinin, müşterilerin demografik özelliklerine göre farklılık gösterip göstermediğini incelemek tir. Literatür incelendiğinde, çeşitli satış tutundurma araçlarının müşteri bağlıı̆̆ı ve satınalma davranışı veya reklamların sadakat ve güven yaratma üzerindeki etkisi ya da mağaza imajının aynı şekilde memnuniyet, sadakat, satınalma davranışı üzerindeki etkisini ayrı ayrı a raştıran birçok çalışmaya rastlamak mümkündür. Her üç değişkeni de birlikte ele alan bir çalışmaya rastlanamamıştır. Çalışma bu noktada literatüre katkı sağlamak bakımından önem taşımaktadır.

\section{LiTERATÜR INCELEMESi}

Satış tutundurma, bir mal ya da hizmetin kısa vadede satın alınmasını teşvik etmek, satışları arttırmak ve diğer tutundurma çabalarını desteklemek amacıyla nihai tüketicilere, aracılara, işletmenin satış gücüne ya da kurumsal müşterilere yönelik yapılan faaliy etlerdir (Gülçubuk, 2007:59; Kotler ve Armstrong, 2018:494; Yükselen, 2019:313). Satınalma kararlarının ortalama \%70'inin satış noktalarında yapıldığı düşünüldüğünde (Gülçubuk, 2007:59), tüketicilere yönelik satış tutundurma faaliyetlerinin tüketicileri satış noktalarına çekmek, mevcut müşterilerin daha fazla mal ya da hizmet almala rını sağlamak, daha önce işletmeden hiç mal ya da hizmet almayan müşterin ürünü denemelerini gerçekleştirmek veya müşterilerin rakip işletmelere yönelmesini engellemek amacıyla yapıldığı söylenebilir (Yüks elen, 2019:314). Satış tutundurma araçlarından özellikle sürekli fiyat indirimi gibi satış tutundurma araçlarının müşteriler üzerinde düşük kalite algıSı, düşük satınalma ve başka markaya yönelme gibi olumsuz sonuçlar doğurduğunu belirten çalışmalar (Yoo vd., 2000:195-211; Mendez vd., 2015:103-117) olmasına rağmen birçok çalışmada satış tutundurma araçlarının müşteri tutumu, müşteri bağlıı̆ı, satınalma niyeti ve satınalma davranışını olumlu yönde etkilediğine yönelik bulgulara rastlanmaktadır (Göktaş ve Tarakçı, 2018:50-67; Başfırıncı vd., 2019:277300; Sarı ve Kulualp, 2019:48-69).

Reklam, işletmelerin mal, hizmet ve fikirlerini, belirli bir ücret karşılı̆ında, kitle iletişim araçlarıyla hedef pazara tanıtması ve benimsetilmesidir (Mucuk, 2012:184). Reklam da satış tutundurma araçları da bir mal ya da hizmetin satın alınması amacıyla müşterilere gerekçeler sunmaktadır. Satış tutundurma sadece bu davranışın hemen- şimdi gerçekleşmesi amacıyla bunu yapmaktadır (Kotler ve Keller, 2018:600). Pazarlama denince akla ilk gelen, en etkili ve en çok kullanılan iletişim aracı reklamlardır (Tek ve Özgül, 2005:661). Literatürde reklam konusunda yapılan çalışmalar incelendiğinde, reklamın; markalar ve satınalma kararları üzerinde olumlu etkileri olduğuna yönelik bulguların ortaya konduğu görülmektedir (Göktaş ve Tarakçı, 2018:50-67; Durmuş ve Battal, 2018:199-224; Baydaş ve Yaşar, 2019:204-217; Başfırıncı vd., 2019:277-300).

Mağaza imajı ise, müşterinin gözünde mağazanın algılanma biçimidir (Pan ve Zinkhan, 2006:231). Mağazanın olgusal ve duygusal malzemeleriyle birlikte mağazaya ilişkin düşünceleri ve duyguları da kapsar (Oxenfeldt, 1974-1975:9). Yapılan araştırmalarda olumlu mağaza imajının müşteri memnuniyetini ve sadakatini arttırdığı, müşteride güven yarattığı, ağızdan ağıza pazarlama yoluyla da satına Ima kararları üzerinde etkili olduğu sonuçlarına ulaşılmıştır (Pan ve Zinkhan, 2006:229-243; Zengin ve Kılıç, 2018:497-525; Gürbüz ve Başkol, 2019:172201; Türk ve Ünal, 2019:260-280). Satış tutundurma, reklam ve imaj arasındaki ilişkiyi inceleyecek olursak, öncelikle perakendecilikte mağaza imajı oluşturmada reklamın etkisinden söz edilebilir. Reklamlar, bilgilendirme, ikna etme, hatırlatma ve değer katma amaçlarını yerine getirirken aynı zamanda müşteri zihninde bir imaj inşa etmektedir. Satış tutundurma araçları da bu imaj yaratma sürecini kısa vadede yaratarak etkin bir rol üstlenmektedir. Satış tutundurma araçlarıyla geleneksel reklamla oluşturulan olumlu hava pekiştirilir ve sağlamlaştırılır (Gülçubuk, 2007:71). Martineau da (1958:58), perakendecilikte yapılan reklamın mağaza imajını yansıtmada önemli bir faktör olduğunu ifade etmiştir.

\section{YÖNTEM}

Araştırmanın amacı, perakende giyim mağazalarında yapılan satış tutundurma faaliyetleri ve reklamlar ile mağaza imajının müşterilerin satınalma davranışındaki etkisini ölçmektir. Ayrıca, söz konusu etkinin, müşterilerin demografik özelliklerine göre farklılık gösterip göstermediği incelenmektedir. Her birinin etkisinin ayrıayrıaraştırıldığıçalışmaların ötesinde, satış tutundurma, mağaza reklamlarıve mağaza imajının bir bakıma karşılaştırmalı olarak müşterilerin satınalma davranışı üzerindeki etkisinin birlikte çalışılmış olmasının, önemli bir farklılık yaratması beklenmektedir. Bu, hem akademik açıdan önem taşımakta hem de uygulamada perakendecilere yol göstermektedir. Araştırmanı kavramsal modeli Şekil 1'deki gibi olup bu model ile ilgili olarak kullanılan ölçeklerin alındığı kaynaklar aşağıda gösterilm iştir.

Şekil 1: Araştırmanın Modeli

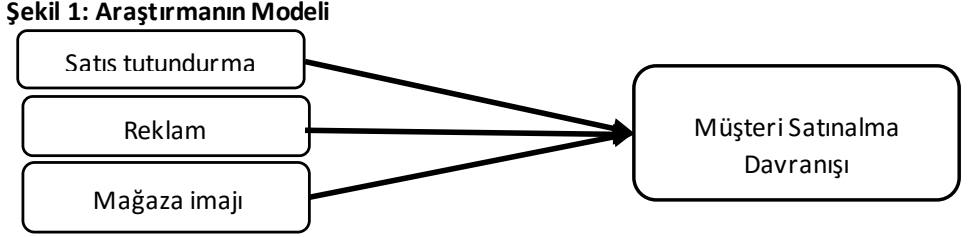

Satış Tutundurma ve Reklam; Yoo ve Chang (2005), Mağaza imajı; Baker vd., (1994), Satınalma davranışı; Lam (2007).

Araştırmanın anakütlesi, Muğla'da faaliyet gösteren bir bölümlü mağazanın müşterileridir. Örneklem büyüklüğü şu şekilde belirlenmiştir (Yükselen, 2017, 67):

$n=p^{*} q *(Z / e)^{2} \rightarrow n=0,5 * 0,5 *(1,96 / 0,05)^{2}=384$

Araştırma hipotezleri literatür çalışmaları ışığında şu şekilde belirlenmiştir: 
H1: Mağazanın satış tutundurma ve reklam faaliyetleri müşterilerin satınalma davranışını olumlu yönde etkiler.

H2: Mağazanın imajı, müşterilerin satınalma davranışını olumlu yönde etkiler.

H3: Mağazanın tutundurma faaliyetleri ve mağaza imajı, birlikte müşterilerin satınalma davranışını olumlu yönde etkiler.

H4: Mağazanın tutundurma faaliyetleri ve mağaza imajının birlikte müşterilerin satınalma davranışına etkisi, müşterilerin cinsiyetlerine göre farklıdır.

H5: Mağazanın tutundurma faaliyetleri ve mağaza imajının birlikte müşterilerin satınalma davranışına etkisi, müşterilerin yaş gruplarına göre farklıdır.

H6: Mağazanın tutundurma faaliyetleri ve mağaza imajının birlikte müşterilerin satınalma davranışına etkisi, müşterilerin medeni durumlarına göre farklıdır.

H7: Mağazanın tutundurma faaliyetleri ve mağaza imajının birlikte müşterilerin satınalma davranışına etkisi, müşterilerin öğrenim durumlarına göre farklıdır.

Örnekleme girecek müşteriler, kolayda örnekleme yöntemi ile seçilmiştir. Bu amaçla söz konusu mağazaya iki hafta boyunca gelen müşterilerle yüz yüze görüşmeler yapılarak anketler toplanmıştır. Anket formunda toplamda 22 soru sorulmuştur (Demografik özellikler:4, satış tutundurma faaliyetleri:5, reklamlar:4, mağaza imajı:4 ve satınalma davranışı:5). Söz konusu değişkenlerine ilişkin sorular için 5 'li Likert ölçeği (1:Kesinlikle Katılmıyorum, 5:Kesinlikle Katılıyorum) kullanılmıştır.

\section{BULGULAR}

Araştırmanın güvenilirliğini arttırmak amacıyla toplamda 500 anket yüz yüze uygulanmıştır. Eksik ve hatalı anketler elendiğinde 404 adet anket formunun kullanılabilir durumda olduğu tespit edilmiştir. Araştırmaya katılanmüşterilerin demografik özelliklerine ilişkin bulgular Tablo 1'de gösterilmiştir. Tablo 1 incelendiğinde, araştırmaya katılan müşterilerin büyük çoğunluğunun 31-45 yaş aralığında (\%53,7), üniversite mezunu (\%49), evli $(\% 67,8)$ ve kadın (\%59) olduğu görülmektedir.

\section{Tablo 1: Cevaplayıcılara ilişkin Demografik Bilgiler}

\begin{tabular}{|c|c|c|c|c|c|}
\hline Cinsiyet & $\mathrm{n}$ & $\%$ & Medeni Durum & $\mathrm{n}$ & $\%$ \\
\hline Kadın & 198 & 59,0 & Bekar & 130 & 32,2 \\
\hline Erkek & 206 & 41,0 & Evli & 274 & 67,8 \\
\hline Toplam & 404 & 100,0 & Toplam & 404 & 100,0 \\
\hline \multicolumn{3}{|l|}{ Yaş } & \multicolumn{3}{|l|}{ Eğitim Durumu } \\
\hline $18-30$ & 66 & 16,3 & ilköğretim & 56 & 13,9 \\
\hline $31-45$ & 217 & 53,7 & Lise & 150 & 37,1 \\
\hline 46 ve üstü & 121 & 30,0 & Üniversite & 198 & 49,0 \\
\hline Toplam & 404 & 100,0 & Toplam & 404 & 100,0 \\
\hline
\end{tabular}

Tablo 2' de model değişkenlerine ilişkin Cronbach's Alpha değerleri gösterilmektedir. Güvenilirlik analizi sonuçlarına bakıldığında modelde yer alan değişkenlere ilişkin ölçeklerin güvenilirlik katsayılarının yüksek olduğu söylenebilir.

Tablo 2: Model Değişkenlerine ilişkin Güvenilirlik Analizi Sonuçları

\begin{tabular}{|l|l|l|}
\hline Değişkenler & Soru Sayısı & Cronbach's Alpha \\
\hline Satıs Tutundurma & 5 & 0,787 \\
\hline Reklam & 5 & 0,922 \\
\hline Mağaza imajı & 4 & 0,875 \\
\hline Satınalma davranışı & 5 & 0,715 \\
\hline
\end{tabular}

Mağazanın satış tutundurma ve reklam faaliyetlerinin müşterilerin satınalma davranışı üzerindeki etkisi çoklu regresyon analizi ile test edilmiş olup sonuçlar Tablo 3,4 ve 5'de gösterilmiştir. Analiz sonuçlarına göre, satış tutundurma ve reklam faaliyetleri ile müşterilerin satınalma davranışı arasındaki ilişkinin zayıf olduğu $(r=0,194)$, modelin \%5 önem derecesinde anlamlı çıktığı (Tablo 4) ve satış tutundurma faaliyetlerinin bu etkide istatistiksel olarak önemli bir rol oynadığı (Tablo 5) görülmektedir. Dolayısıyla H1 hipotezi kabul edilmiştir.

Tablo 3: Satış Tutundurma ve Reklam Faaliyetleri ile Müşterilerin Satınalma Davranışı ilişkisi Model Özeti

\begin{tabular}{|c|c|c|c|c|}
\hline Model & $\mathbf{R}$ & $R^{2}$ & püzeltilmiş $R^{2}$ & Tahminin Standart Hatası \\
\hline & 0,194 & 0,037 & $\mathrm{p}, 033$ & 0,49336 \\
\hline
\end{tabular}

Tablo 4: Satış Tutundurma ve Reklam Faaliyetlerinin Müşterilerin Satınalma Davranışı Üzerindeki Etkisine ilişkin Regresyon Modeli ANOVA Sonuçları

\begin{tabular}{|c|c|c|c|c|c|}
\hline Model & Karelerin Toplamı & $S d$ & \begin{tabular}{|l|} 
Karelerin \\
Ortalaması
\end{tabular} & $\mathbf{F}$ & p \\
\hline Regresyon & 3,774 & 2 & 1,887 & 7,752 & 20,000 \\
\hline Artık & 96,875 & 398 & 243 & & \\
\hline Toplam & 100,649 & 400 & & & \\
\hline
\end{tabular}

Tablo 5: Satış Tutundurma ve Reklam Faaliyetlerinin Müşterilerin Satınalma Davranışı Üzerindeki Etkisine ilişsin Regresyon Modeli Katsayıları

\begin{tabular}{|c|c|c|c|c|c|c|c|}
\hline & \multicolumn{2}{|c|}{$\begin{array}{ll}\text { Standardize } & \text { Olmayan } \\
\text { Katsayılar } & \\
\end{array}$} & \multirow{2}{*}{$\begin{array}{l}\text { Standardize Katsayılar } \\
\text { Beta }\end{array}$} & \multirow{2}{*}{$t$} & \multirow{2}{*}{ p } & \multicolumn{2}{|c|}{ Eşkökenlik } \\
\hline & B & Standart Hata & & & & Tölerans & VIF \\
\hline Sabit & 4,070 & ,119 & & 34,207 & 000 & & \\
\hline Reklam & ,038 & 022 &, 092 & 1,676 & 095 & 811 & 1,233 \\
\hline Satış Tutundurma & 084 & ,034 & ,135 & 2,480 & 014 & 811 & 1,233 \\
\hline
\end{tabular}


Mağaza imajının satınalma davranışını üzerindeki etkisi basit regresyon analizi ile test edilmiş olup sonuçlar Tablo 6, 7 ve 8' de gösterilmiştir. Analiz sonuçlarına incelendiğinde, iki değişken arasındaki korelasyon katsayısının 0,613 olduğu (Tablo 6), modelin anlamlı çıtı̆̆ı (Tablo 7), mağaza imajı ile satınalma davranışı arasında güçı̈ bir ilişki olduğu ve mağaza imajının satınalma davranışındaki değişimin \% $37,5^{\prime}$ ini açıkladığı saptanmıştır. Sonuç olarak $\mathrm{H} 2$ hipotezi kabul edilmiştir.

Tablo 6: Mağaza İmajı ve Satınalma Davranışı ilişsisi Model Özeti

\begin{tabular}{|l|l|l|l|l|}
\hline Model & $\mathbf{R}$ & $\mathbf{R}^{2}$ & Düzeltilmiş $\mathbf{R}^{2}$ & Tahminin Standart Hatası \\
\hline & 0,613 & 0,376 & 0,375 & 0,39616
\end{tabular}

Tablo 7: Mağaza İmajının Satınalma Davranışı Üzerindeki Etkisine iliş̧kin Regresyon Modeli ANOVA Sonuçları

\begin{tabular}{|l|l|l|l|l|l|}
\hline Model & Karelerin Toplamı & Sd & Karelerin Ortalaması & F & $\mathbf{p}$ \\
\hline Regresyon & 37,939 & 1 & 37,939 & 241,741 & 0,000 \\
\hline Artık & 62,933 & 401 & 157 & & \\
\hline Toplam & 100,872 & 402 & & &
\end{tabular}

Tablo 8: Mağaza İmajının Satınalma Davranışı Üzerindeki Etkisine ilişsin Regresyon Modeli Katsayıları

\begin{tabular}{|c|c|c|c|c|c|}
\hline \multirow{2}{*}{ Model } & \multicolumn{2}{|c|}{ Standardize Olmayan Katsayılar } & \multirow[t]{2}{*}{ Standardize Katsayılar } & \multirow{2}{*}{ Model } & \multirow{2}{*}{ p } \\
\hline & B & Standart Hata & & & \\
\hline Sabit & 2,372 & 139 & & 17,026 & 000 \\
\hline Mağaza imajı & 481 & 031 & 613 & 15,548 & 000 \\
\hline
\end{tabular}

Mağazanın satış tutundurma ve reklam faaliyetleri ile mağaza imajının müşterilerin satınalma davranışı üzerindeki etkisi çoklu regresyon analizi ile test edilmiş olup sonuçlar Tablo 9, 10 ve 11' de gösterilmiştir. Analiz sonuçlarına bakıldığında iki grup değişken arasındaki korelasyon katsayısının 0,615 olduğu (Tablo 9), modelin anlamlı çıktığı (Tablo 10), bu etkide temel rol oynayan değişkenin ise mağaza imajı olduğu, dolayısıyla H3 hipotezinin \%5 önem derecesinde kabul edildiği söylenebilir.

Tablo 9: Satış Tutundurma Faaliyetleri, Reklam ve Mağaza İmajı İe Müşterilerin Satınalma Davranışı ilişkisi Model Özeti

\begin{tabular}{|l|l|l|l|l|}
\hline Model & $\mathbf{R}$ & $\mathbf{R}^{2}$ & Düzeltilmiş $\mathbf{R}^{\mathbf{2}}$ & Tahminin Standart Hatası \\
\hline & 0,615 & 0,378 & 0,374 & 0,39728 \\
\hline
\end{tabular}

Tablo 10: Satış Tutundurma Faaliyetleri, Reklam ve Mağaza İmajının Satınalma Davranışı Üzerindeki Etkisine ilişkin Regresyon Modeli ANOVA Son uçları

\begin{tabular}{|l|l|l|l|l|l|}
\hline Model & Karelerin Toplamı & Sd & Karelerin Ortalaması & $\mathbf{F}$ & $\mathbf{p}$ \\
\hline Regresyon & 38,050 & 3 & 12,683 & 80,362 & 0,000 \\
\hline Artık & 62,500 & 396 & 158 & & \\
\hline Toplam & 100,550 & 399 & & & \\
\hline
\end{tabular}

「ablo 11: Satış Tutundurma Faaliyetleri, Reklam ve Mağaza İmajııın Satınalma Davranışı Üzerindeki Etkisine ilişkin Regresyon Modeli Katsayıları

\begin{tabular}{|c|c|c|c|c|c|c|c|}
\hline & \multicolumn{2}{|c|}{ Standardize olmayan katsayılar } & \multirow{2}{*}{$\begin{array}{l}\text { Standardize katsayllar } \\
\text { Beta }\end{array}$} & \multirow{2}{*}{$\mathbf{t}$} & \multirow{2}{*}{ p } & \multicolumn{2}{|c|}{ Eşkökenlik } \\
\hline & B & Standart Hata & & & & Tölerans & VIF \\
\hline Sabit & 2,401 & ,149 & & 16,134 &, 000 & & \\
\hline Satış Tutundurma &,- 009 & 028 &,- 014 &,- 316 & ,752 & ,775 & 1,290 \\
\hline Reklam &,- 017 & 018 &,- 040 &,- 898 & 370 & ,784 & 1,276 \\
\hline Mağaza İmajı & 494 & 033 & 631 & 14,757 & 000 & 860 & 1,163 \\
\hline
\end{tabular}

Satış tutundurma, reklam ve mağaza imajının müşterinin satınalma davranışına etkisinin demografik faktörleregörefarklııkla rının test edildiği H4, H5, H6 ve H7 hipotezlerinin analiz sonuçları Tablo 12' de verilmiştir. Cinsiyete göre farklılıklar incelendiğinde, mağaza imajının kadınlarda erkeklerden daha yüksek etkiye sahip olduğu görülmektedir. Yaş gruplarına göre farklılıklar incelendiğinde, 18-30 yaş grubu ile 31-45 yaş grubunda reklamın etkisini gösteren regresyon katsayıları anlamlı çıkmış olmakla beraber, 31-45 yaş grubunda negatif bir etki olduğu görülmektedir. Mağaza imajının her üç yaş grubunda anlamlı bir etkiye sahip olduğu, 18-30 yaş grubunda diğerlerine göre mağaza imajının daha düşük bir etkiye sahip olduğu görülmektedir. Medeni duruma göre farklılıklar incelendiğinde, mağaza imajının etkisinde bekarlar lehine küçük bir farklılığın olduğu görülmektedir. Öğrenim durumuna göre farklılıklar incelendiğinde ise, ilköğretim mezunlarında reklam ve mağaza imajının etkili olduğu, ancak reklamın etkisinin ters yönde gerçekleştiği; buna karşılık aynı grupta mağaza imajının etkisinin diğer g ruplara göre daha yüksek olduğu görülmektedir. Dolayısıyla H4, H5, H6 ve H7 hipotezleri kabul edilmiştir.

Tablo 12: Satış Tutundurma, Reklam ve Mağaza İmajının Müşterinin Satınalma Davranışına Etkisinin Demografik Özelliklere Göre Farklııklarının Testi

\begin{tabular}{|l|l|l|l|l|l|l|l|l|l|}
\hline & Regresyon Modeli & \multicolumn{1}{l|}{ Satış Tutundurma } & \multicolumn{1}{l|}{ Reklam } & Mağaza Imajı \\
\hline & F & $\mathbf{p}$ & $\mathbf{B}$ & $\mathbf{p}$ & $\mathbf{B}$ & $\mathbf{p}$ & B \\
\hline
\end{tabular}




\begin{tabular}{|l|l|l|l|l|l|l|l|l|l|}
\hline Bekar & 28,665 & 0,000 & $-0,037$ & 0,543 & $-0,003$ & 0,929 & 0,501 & 0,000 \\
\hline Evli & 50,256 & 0,000 & 0,010 & 0,754 & $-0,020$ & 0,352 & 0,484 \\
\hline Öğrenim Durumu \\
\hline Ilköğretim & 10,782 & 0,000 & 0,002 & 0,980 & $-0,125$ & 0,021 & 0,000 \\
\hline Lise & 19,748 & 0,000 & 0,005 & 0,927 & $-0,019$ & 0,587 & 0,439 \\
\hline Üniversite & 53,291 & 0,000 & $-0,018$ & 0,648 & 0,010 & 0,685 & 0,490 & 0,000 \\
\hline
\end{tabular}

\section{SONUÇ VEÖNERILER}

Bölümlü mağazalara yönelik olarak yapılan söz konusu araştırmanın sonuçları incelendiğinde, satış tutundurma ve reklam faaliyetlerinin müşterilerin satınalma davranışını olumlu yönde etkilediği, bu etkide satış tutundurma faaliyetlerinin istatistiksel olarak önemli bir rol oynadığı, mağaza imajının satınalma davranışını olumlu yönde etkilediği, satış tutundurma faaliyetleri ve mağaza imajının satınalma davranışı olumlu yönde etkilediği, bu etkide mağaza imajının istatistiksel olarak önemli bir rol oynadığı, mağazanın satış tutundurma faaliyetleri ve mağaza imajının birlikte müşterilerin satınalma davranışına etkisinin müşterilerin cinsiyetlerine, yaş gruplarına, medeni ve öğrenim durumlarına göre farklılık gösterdiği söylenebilir.

Araştırmaya ilişkin bulgulardan yola çıkılarak, satış tutundurma araçları, reklam ve mağaza imajının müşterilerin mağaza tercihinde ve satınalma davranışlarında etkili olduğu; mağaza imajı geliştirme çalışmalarına ayrı bir önem vermeleri, tutundurma faaliyetle ri ile mağaza imajına katkı vermeye çalışmaları, ayrıca mağaza atmosferi unsurlarına önem vererek, kendilerini diğer mağazalardan farklı kılacak bir imaj yaratmaya destek vermeleri gerektiği söylenebilir. Ancak araştırma verilerinin bir bölümlü mağazada ve belirli bir dönemde toplanmış olmasının önemli bir kısıt olması sebebiyle söz konusu sonuçları genellemek mümkün değildir. İleride yapılacak çalışmalar açısından araştırmanın farklı mağazalarıveya mağaza zincirlerinikapsayacak şekilde yapılması, çalışma modelinin farklızaman aralıkla rında test edilmesi önerilebilir. Böylelikle tüketici satınalma davranışlarıyla satış tutundurma, reklam ve mağaza imajı arasındaki ilişkiyi belirlemeye yönelik literatürün daha da derinleşeceği söylenebilir.

\section{KAYNAKÇA}

Arslan, M. ve Boyçu, S. (2006). Mağaza Atmosferi. (Ed. M. Oyman) Eskişehir:T.C. Anadolu Üniversitesi Yayın No:1696, Açık öğretim Fakültesi Yayını: 881.

Baker, J., Grewal, D. ve Parasuraman, A. (1994). The Influence of Store Environment on Quality Inferences and Store Image. Journal of the Academy of Marketing Science, 22, 328-339.

Başfırıncı, Ç., Çilingir Ük, Z. ve Gültekin, Y. (2019). Türkiye'deki İndirim Marketlerinin Marka İmajlarının Sosyal Ağ Analizi Yöntemiyle İncelenmesi: A101, BìM ve ŞOK Örneği. Uluslararası Ekonomi ve Yenilik Dergisi, 5(2), 277-300.

Baydaş, A. ve Yaşar, M. E. (2019). Reklam ve Etkili Reklam Unsurlarının Belirlenmesine Yönelik Uygulamalı Bir Araştırma. Uluslararası Batı Karadeniz Sosyal ve Beşeri Bilimler Dergisi, 3(2), 204-217.

Durmuş, İ. ve Battal, F. (2018). Tüketicilerin Hazır Giyim Tercihlerinde Marka, Reklam Aracı, Tutum ve Satınalma Karar Verme Tarzları. Sosyal Bilimler Enstitüsü Dergisi, 42, 199-224.

Göktaş, B. ve Tarakçı, İ. E. (2018). Bir Tutundurma Aracı Olarak Reklamın Sosyal Medyada Uygulamalarına Yönelik Bir Araştırma: Instagram Örneği. Girişimcilik Inovasyon ve Pazarlama Araştırmaları Dergisi, 2(3), 50-67.

Gülçubuk, A. (2007). Tüketicilere Yönelik Satış Geliştirmenin Artan Önemi, Uygulanabilirliği ve İzlenecek Stratejilerin İşletmeler Açısından Değerlendirilmesi. Ege Akademik Bakış, 7(1), 57-77.

Gürbüz, E. ve Başkol, M. (2019). Perakendeci Marka Sadakatini Etkileyen Faktörlerin Belirlenmesi. Yönetim, Ekonomi, Edebiyat, İslami ve Politik Bilimler Dergisi, 4(2), 172-201.

Kotler, P. ve Armstrong, G. (2018). Pazarlama İlkeleri. (Çev. A. E. Gegez) Ankara: Beta Basım Yayım Dağıtım A.Ş.

Kotler, P. ve Keller, K. L. (2018). Pazarlama Yönetimi. (Çev. İ. Kırcova) Ankara: Beta Basım Yayım Dağıtım A.Ş.

Martineau, P. (1958). The Personality of the Retail Store. Harvard Business Review, 36, 47-55.

Mendez, M., Bendixen, M., Abratt, R., Yurova, R. ve O'Leary, B. (2015). Sales Promotion and Brand Loyalty: Some New Insights. International Journal of Education and Social Science, 2(1), 103-117.

Mucuk, i. (2012). Pazarlama İlkeleri. İstanbul: Türkmen Kitapevi.

Oxenfeldt, A. R. (1974-1975). Developing a Favorable Price-Quality Image. Journal of Retailing, 50(4), 8-15.

Pan, Y. ve Zinkhan, G. M. (2006). Determinants of Retail Patronage: A Meta Analytical Perspective. Journal of Retailing, 82 (3), $229-243$.

Sarı, Ö. ve Kulualp, H. G. (2019). Tüketici Davranışına Göre Müşteri Sadakat Programı Algısının İlişkisel Pazarlama Kapsamında İncelenmesi. IBAD Sosyal Bilimler Dergisi, 5, 48-69.

Tek, Ö. B. ve Özgül, E. (2005). Modern Pazarlama İlkeleri. İzmir: Birleşik Matbaacılık. 
Türk, M. ve Ünal, A. (2019). Mağaza Atmosferinde Etkili Olan Faktörlerle Memnuniyet sadakat-Tavsiye Etme Durumu Arasındaki i̇lişkiyi Belirlemeye Yönelik Bir Alan Çalışması. C.Ü. Iktisadi ve Idari Bilimler Dergisi, 20(1), 260-280.

Yoo, B., Donthu, N. ve Lee, S. (2000). An Examination of Selected Marketing Mix Elements and Brand Equity. Journal of the Academy of Marketing Science, 28(2), 195-211.

Yoo, S. J. ve Chang, Y. J. (2005). An Exploratory Research on the Store Image Attributes Affecting Its Store Loyalty. Seoul Journal of Business, $11(1), 19-41$.

Yükselen, C. (2017). Pazarlama Araştırmaları. Ankara: Detay Yayıncılık.

Yükselen, C. (2019). Dijitalleşme Sürecinde Pazarlama, illkeler, Yönetim, Örnek Olaylar. Ankara: Detay Yayıncılık.

Zengin, B. ve Kılıç, S. (2018). Mağaza İmajının Alışverişçi Hareketliliği Üzerindeki Etkisi: Bursa İlinde Bir Uygulama. Balıkesir Üniversitesi Sosyal Bilimler Enstitüsü Dergisi, 21(40), 497-525. 